\title{
Lactic Acid Bacteria Isolated from Japanese Fermented Fish (Funa-Sushi) Inhibit Mesangial Proliferative Glomerulonephritis by Alcohol Intake with Stress
}

\author{
Yumiko Yamada, ${ }^{1}$ Masumi Endou, ${ }^{2}$ Shunichi Morikawa, ${ }^{3}$ Jun Shima, ${ }^{4}$ and \\ Noriko Komatshzaki $\mathbb{1}^{2}$ \\ ${ }^{1}$ Nodakamada Gakuen, 389-1 Noda, Noda, Chiba 278-0037, Japan \\ ${ }^{2}$ Department of Human Nutrition, Seitoku University, 550 Iwase, Matsudo, Chiba 271-8555, Japan \\ ${ }^{3}$ Department of Anatomy and Developmental Biology, Tokyo Women's Medical University, 8-1 Kawada-Cho, Shinjuku, Tokyo \\ 162-8666, Japan \\ ${ }^{4}$ Faculty of Agriculture, Ryukoku University, 1-5 Yokotani, Seta Oe-cho, Otsu, Shiga 520-2194, Japan
}

Correspondence should be addressed to Noriko Komatshzaki; norikoma@seitoku.ac.jp

Received 10 August 2017; Revised 25 November 2017; Accepted 12 December 2017; Published 11 February 2018

Academic Editor: Stan Kubow

Copyright (c) 2018 Yumiko Yamada et al. This is an open access article distributed under the Creative Commons Attribution License, which permits unrestricted use, distribution, and reproduction in any medium, provided the original work is properly cited.

\begin{abstract}
The aim of this study was to examine the effect of heat-killed Lactobacillus paracasei NFRI 7415 on kidney and bone in mice fed an ethanol-containing diet with stress. Eight-week-old Cril : CD1 mice were fed a control diet (CD), an alcohol diet (AD) (35.8\% of total energy from ethanol), or an alcohol diet containing $20 \%$ heat-killed Lb. paracasei NFRI 7415 ( $10^{7}$ CFU/g) (LD) for 4 weeks. Mice in the $\mathrm{AD}$ and $\mathrm{LD}$ groups also underwent restraint stress for two weeks from 13 days. The mice were placed in a $50 \mathrm{~mL}$ plastic tube, which had a small hole drilled around its base to allow ventilation, and restrained for $1 \mathrm{~h}$ every day. High final body weight was in the following order: $\mathrm{CD}, \mathrm{LD}$, and $\mathrm{AD}(p<0.05)$. The heat-killed Lb. paracasei NFRI 7415 lowered liver total cholesterol concentration and plasma glutamic-oxaloacetic transaminase (GOT) level. In addition, fecal bile acids of the LD group were higher than in the $\mathrm{AD}$ group $(p<0.05)$. The glomerulus of the kidney in the $\mathrm{AD}$ group was observed to be more fibrotic than in the $\mathrm{CD}$ and LD groups with azan stain. Immunostaining confirmed that brown areas indicating the existence of mesangial cells were increased in the AD group, but not in the CD and LD groups. These results indicated that the heat-killed Lb. paracasei NFRI 7415 inhibited mesangial proliferative glomerulonephritis by alcohol intake with stress.
\end{abstract}

\section{Introduction}

People are subjected to many stressors in modern life, including both physical and mental stresses. Excessive stress can cause psychosomatic disorders, and sometimes death from overwork [1]. In recent years, lifestyle-related diseases are in most cases caused by overwork, excessive stress, sleep deprivation, smoking, and drinking [2]. It is well known that chronic ethanol consumption induces osteoporosis and chronic nephritis [3-5].

Lactic acid bacteria (LAB) have been utilized as a natural health food since ancient times, and the health-promoting effects of LAB are well recognized [6]. Some LAB are used in food fermentation, and typical examples can be found in the dairy industry for the production of cheese, yogurt, and other fermented milk products $[7,8]$.

Recent studies have indicated that several LAB are effective as probiotics for the prevention of osteoporosis and chronic nephritis. For example, Bifidobacterium longum alleviated bone loss in ovariectomized rats and enhanced bone mass density [9]. It was reported that yogurt consumption retarded chronic kidney disease progression [10].

Lactobacillus paracasei NFRI 7415, isolated from traditional Japanese fermented fish (funa-sushi), showed high $\gamma$-aminobutyric acid (GABA)-producing ability [11]. We reported that $L b$. paracasei NFRI 7415 removed cholesterol 
from the plasma and liver of rats fed an ethanol-containing diet [12]. Moreover, it was shown that this strain reduced the content of liver lipids in C57BL/6J mice fed a high-fat diet [13]. We speculated that $L b$. paracasei NFRI 7415 might have improved liver function in the abovementioned clinical study by somehow reducing hepatic lipid content. To the best of our knowledge, no study has investigated the effect of $L b$. paracasei in the kidney of rat with stress and chronic ethanol consumption.

The aim of the present study was to examine the effect of heat-killed $L b$. paracasei NFRI 7415 on the kidney and bone in mice fed an ethanol-containing diet with stress. We investigated body and fat tissue weight, as well as calcium in the bone and tissues of the kidney in mice. Symptoms associated with glomerulonephritis are hyperlipidemia and proteinuria [14]. It has been reported that supply of amino acid-fortified low-protein diets to nephritic rats improved their symptoms, and fecal bile acid excretion was enhanced [15]. Thus, we focused on the effect of fecal bile acid excretion by $L b$. paracase $i$ NFRI 7415 and investigated the fecal lipids of mice.

\section{Materials and Methods}

2.1. Preparation of Extract. A preculture of Lb. paracasei NFRI 7415 was grown to the stationary phase at $37^{\circ} \mathrm{C}$ for $20 \mathrm{~h}$ in MRS agar medium (Difco Laboratories, Detroit, MI). The medium was prepared by mixing an alcohol diet (AD) and sterilized water at a ratio of $1: 3$. The precultures $\left(10^{7} \mathrm{CFU} / \mathrm{g}\right)$ were inoculated in 0.4 liters of $\mathrm{AD}$ at $37^{\circ} \mathrm{C}$ for $48 \mathrm{~h}$. The medium was then heated at $100^{\circ} \mathrm{C}$ for $30 \mathrm{~min}$ and used in the animal experiments.

2.2. Animals and Diets. Twenty-four 8-week-old Cril : CD1 mice were purchased from Charles River Japan (Yokohama, Japan). All animals were housed individually in plastic cages in a controlled environment of $22 \pm 1^{\circ} \mathrm{C}$ at $50 \%$ relative humidity under a $12 \mathrm{~h}$ dark/light cycle (19:00-7:00). The animals were randomly divided into three dietary treatment groups with equal mean body weight: the control diet (CD) group $(n=8)$, the alcohol diet (AD) group $(n=8)$, and the heated medium with $L b$. paracasei NFRI $7415\left(10^{7} \mathrm{CFU} / \mathrm{g}\right)$ and alcohol diet bended at a ratio of $1: 4(\mathrm{LD})$ group $(n=8)$.

Composition of the liquid diets (CD, AD, and $\mathrm{LD})$ is given in Table 1; diets were formulated with reference to the Lieber-DeCarli diet [16]. All liquid diets were freshly prepared on alternate days. The mice were fed the $\mathrm{CD}, \mathrm{AD}$, or LD for 4 weeks. Food intake was recorded daily, and body weight was measured on alternate days. The mice of AD and LD group were subjected to restraint stress for two weeks from day 13 after feeding. Restraint stress was made with reference to the method of De Francesco et al. [17]. The mice were placed in a $50 \mathrm{~mL}$ plastic tube, which had a small hole drilled around its base to allow ventilation, and restrained for $1 \mathrm{~h}$ every day (Figure 1). Then, experimental mice were returned to their home cages. After the feeding period, the mice were fasted for $16 \mathrm{~h}$ and sacrificed humanely under ether anesthesia to collect the liver, kidney, and perirenal fat
TABle 1: Composition of experimental diets.

\begin{tabular}{|c|c|c|c|}
\hline Ingredient $(\mathrm{g} / \mathrm{L})$ & $\mathrm{CD}^{1}$ & $\mathrm{AD}^{2}$ & $\mathrm{LD}^{3}$ \\
\hline Casein & 41.4 & 41.4 & 41.4 \\
\hline L-cystine & 0.5 & 0.5 & 0.5 \\
\hline DL-methionine & 0.3 & 0.3 & 0.3 \\
\hline Corn oil & 8.5 & 8.5 & 8.5 \\
\hline Olive oil & 28.4 & 28.4 & 28.4 \\
\hline Safflower oil & 2.7 & 2.7 & 2.7 \\
\hline Vitamin mixture ${ }^{4}$ & 2.5 & 2.5 & 2.5 \\
\hline Mineral mixture ${ }^{5}$ & 8.75 & 8.75 & 8.75 \\
\hline Maltose dextrin mixture & 115.2 & 25.6 & 25.6 \\
\hline Cellulose & 10.0 & 10.0 & 10.0 \\
\hline Choline bitartrate & 0.53 & 0.53 & 0.53 \\
\hline Xanthan gum & 3.0 & 3.0 & 3.0 \\
\hline Ethanol & - & 50.0 & 50.0 \\
\hline Lb. paracasei extract & - & - & $\left(10^{7} \mathrm{CFU} / \mathrm{g}\right)$ \\
\hline
\end{tabular}

${ }^{1} \mathrm{CD}$, control diet; ${ }^{2} \mathrm{AD}$, alcohol diet; ${ }^{3} \mathrm{LD}, \mathrm{Lb}$. paracasei-containing alcohol diet; ${ }^{4}$ vitamin mixture (g/kg of mix): retinal, 4.8 ; cholecalciferol, 0.4 ; thiamine, 24.0; riboflavin, 0.6; pantothenic acid, 0.6; pyridoxine, 0.7; cobalamin, 0.01 ; menadione, 0.05 ; nicotinic acid, 3.0; D-calcium pantothenic acid, 1.6; folic acid, 0.2; biotin, 0.02; para-aminobenzoic acid, 5.0; inositol, 10.0; glucose, $949.02 ;{ }^{5}$ mineral mixture (g/kg of mix): $\mathrm{CaHPO}_{4}, 500.0 ; \mathrm{NaCl}$, 74.0; $\mathrm{K}_{3} \mathrm{C}_{6} \mathrm{H}_{5} \mathrm{O}_{7} \cdot \mathrm{H}_{2} \mathrm{O}, 220.0 ; \mathrm{K}_{2} \mathrm{SO}_{4}, 52.0 ; \mathrm{MGO}, 24.0 ; \mathrm{MnSO}_{4} \cdot 5 \mathrm{H}_{2} \mathrm{O}, 6.77$; $\mathrm{FeSO}_{4} \cdot 7 \mathrm{H}_{2} \mathrm{O}, 4.95 ; \mathrm{ZnCO}_{3}, 1.6 ; \mathrm{CuCO}_{3} \mathrm{Cu}(\mathrm{OH})_{2} \mathrm{H}_{2} \mathrm{O}, 0.3 ; \mathrm{KlO}_{3}, 0.01$; $\mathrm{NaSeO}_{3}, 0.01 ; \mathrm{CrK}\left(\mathrm{SO}_{4}\right)_{2} \cdot 12 \mathrm{H}_{2} \mathrm{O}, 0.55 ; \mathrm{NaF}, 0.06$; sucrose, 115.75 .

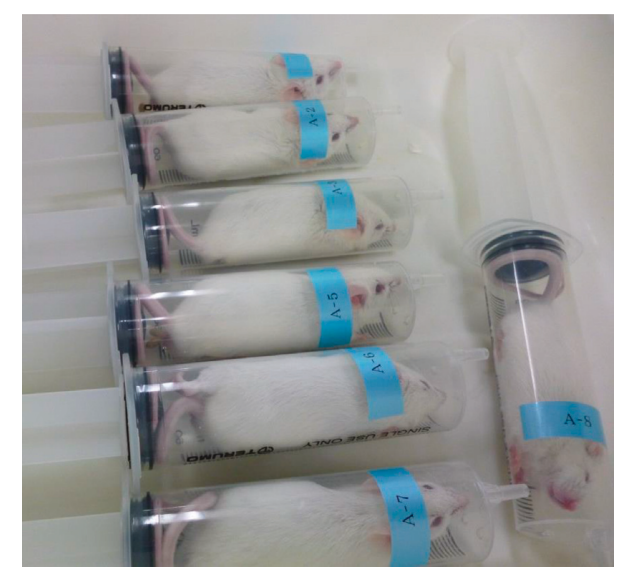

FIgURE 1: Restraint stress. Mice were placed in a $50 \mathrm{ml}$ plastic tube, which had a small hole drilled around its base to allow ventilation, and restrained for $1 \mathrm{~h}$ every day.

tissue. The blood was collected by heart puncture with a heparinized syringe. The blood was maintained at $4^{\circ} \mathrm{C}$ and centrifuged at $1,000 \mathrm{~g}$ for $15 \mathrm{~min}$; the plasma and liver were stored at $-80^{\circ} \mathrm{C}$ until analysis. All procedures were performed in accordance with the Animal Experimentation Guidelines of the Laboratory Animal Care Committee of Seitoku University (approval number 179).

2.3. Biochemical Assays of Plasma and Liver. Liver lipids were extracted by the method described in the work of Folch et al. [18]. Triacylglycerol (TG), total cholesterol (T-cho), 
HDL-cholesterol, glutamic-oxaloacetic transaminase (GOT), and glutamic-pyruvic transaminase (GPT) in plasma and liver extracts were measured using test kits (Triacylglycerol E-Test, Cholesterol E-Test, HDL-cholesterol E-Test, and Transaminase CII-Test, Wako Pure Chemical Industries, Osaka, Japan).

2.4. Assays of Ash, Calcium, and Phosphorus. The right femur was taken and weighed after removing the meat. Ash content in the femur was first treated by drying at $105^{\circ} \mathrm{C}$ for $48 \mathrm{~h}$, then defatted by absolute ether for 3 days. Defatted bone was treated by ashing process at $550^{\circ} \mathrm{C}$ overnight in an electric furnace. The ash in the femur was measured with the weight method [19]. Ash was then added to $10 \mathrm{~mL}$ of $2 \mathrm{~N} \mathrm{HCl}$, and calcium and phosphorus in ash were measured with test kits (Calcium E-Test and Phospha C-Test, Wako Pure Chemical Industries, Osaka, Japan).

2.5. Assay of Fecal Lipids and Fecal Cholesterol. Here, $0.1 \mathrm{~g}$ of homogenized dry fecal matter was added to $4 \mathrm{~mL}$ of concentrated sulfuric acid in test tubes for $30 \mathrm{~min}$ at room temperature. Diethyl ether was added to reach $25 \mathrm{~mL}$, and mixed. The diethyl ether-containing layer was moved to a flask, and the diethyl ether was evaporated. The fecal lipid in the flask was then weighed. The T-cho concentration in fecal matter was determined in the same way as in the liver T-cho concentration.

Fecal bile acids were measured by the procedure described in the work of Iwami et al. [20]; $10 \mathrm{mg}$ of the sample was mixed with $0.2 \mathrm{~mL}$ of $90 \%$ ethanol during vortex mixing and incubated for $1 \mathrm{~h}$ at $65^{\circ} \mathrm{C}$. The mixture was subjected to centrifugation at 5,000 rpm for $3 \mathrm{~min}$. The supernatant was transferred to a $1.5 \mathrm{~mL}$ tube, and the ethanol was evaporated. Then, $0.2 \mathrm{~mL}$ of $90 \%$ ethanol was added in the precipitate for vortex mixing. The sample was dissolved in $1 \mathrm{~mL}$ of $90 \%$ ethanol and measured using test kits (total bile acid test by enzyme colorimetric method, Wako pure Chemical Industries, Osaka, Japan).

2.6. Kidney Histology. Kidneys of mice from the three dietary treatment groups were compared histologically. Under deep anesthesia with ether, the chest of a mouse from the three groups was opened rapidly and the vasculature was perfused with $50 \mathrm{~mL}$ of a fixative (4\% paraformaldehyde in $0.01 \mathrm{M}$ sodium phosphate-buffered saline (PBS: $\mathrm{pH} 7.4)$ ) at a pressure of $120 \mathrm{mmHg}$ from a 18-gauge cannula inserted into the aorta via an incision in the left ventricle. Immediately after fixative perfusion, the kidney was removed, cut into small pieces, and immersed in the same fixative overnight at $4^{\circ} \mathrm{C}$. Kidney pieces were then washed with PBS, dehydrated in an ascending series of ethanol aqueous solutions $(70 \%, 80 \%, 90 \%$, and $100 \%)$, cleared in xylene, and embedded in paraffin wax. Three-micrometer-thick sections of paraffin-embedded kidneys were then subjected to hematoxylin and eosin (H\&E) staining by a routine procedure (Meyer's hematoxylin staining, followed by eosin Y staining) and azan staining by a routine procedure (Mordant, Mallory's azocarmine $\mathrm{G}$ solution, 5\% phosphotungstic acid solution, and Mallory's aniline blue orange $\mathrm{G}$ stain solution). Samples were then examined under a microscope (Olympus CH20 with Shimazu Moticam 580).

2.7. Immunostaining. Deparaffinized and rehydrated $3 \mu \mathrm{m}$ paraffin sections of formaline-fixed kidneys were enzymetreated by protease. The primary antibody used for this study was desmin (West Grove, PA, USA). Secondary antibodies used peroxidase-conjugated AffiniPure Donkey AntiRabbit IgG $(\mathrm{H}+\mathrm{L})$, purchased from Jackson ImmunoResearch (West Grove, PA, USA). Liquid DAB + Substrate Chromogen System (Dako, Tokyo, Japan) were used for the color reaction, after counterstaining with hematoxylin. For confirmation of the mesangial proliferative glomerulonephritis by inducing ethanol intake and restraint stress, the number of the mesangial cells was counted in the 65 glomerulus of the kidney.

2.8. Statistical Analysis. Values were expressed as mean \pm SD. Repeated-measures analysis of variance (ANOVA) was used to evaluate the effects of groups. Differences in mean values between groups were tested by Scheffe multiple-range test. A $p$ value of less than 0.05 was considered statistically significant.

\section{Results}

3.1. Food Intake, Total Energy Intake, Body Weight, Liver, Kidney, and Perirenal Fat Tissue Weight. No significant differences in liver and kidney weights were observed among the three groups. Total energy intake and perirenal fat tissue weight of the $\mathrm{AD}$ and $\mathrm{LD}$ groups were lower than in the $\mathrm{CD}$ group $(p<0.05)$ (Table 2). Figure 2 shows the body weight of mice during the experiment. The final body weight of mice was high in the following order: $\mathrm{CD}, \mathrm{LD}$, and $\mathrm{AD}(p<0.05)$. After the mice in the $\mathrm{AD}$ and $\mathrm{LD}$ groups underwent restraint stress from 13 days, weight between the $\mathrm{AD}$ and $\mathrm{LD}$ groups increased.

3.2. Plasma Lipids Profiles and Liver Lipids. Although no significant differences in plasma TG concentration were observed between the three groups, the plasma T-cho and HDL-cholesterol concentrations of the $\mathrm{AD}$ group were lower than those of the CD and LD groups $(p<0.05)$ (Table 3). No differences were observed in liver total lipids and liver TG concentrations between groups, but liver T-cho concentrations of the $\mathrm{CD}$ and $\mathrm{LD}$ groups were lower than those of the AD group $(p<0.05)$ (Table 3). The plasma GOT level of the $\mathrm{AD}$ group was higher than those of the $\mathrm{CD}$ and $\mathrm{LD}$ groups $(p<0.05)$ (Figure 3$)$. In addition, the plasma GPT level of the $\mathrm{AD}$ group was higher than that of the $\mathrm{CD}$ group $(p<0.05)$ (Figure 3).

3.3. Bone Contents, Plasma Calcium, and Fecal Lipids. The ash content in the bone of the $\mathrm{AD}$ group was lower than those in the $\mathrm{CD}$ and LD groups, although there were no significant differences in right femur weight, calcium, or phosphorus in the bone between the groups $(p<0.05)$ (Table 4). There was also no difference in plasma calcium between groups. No significant differences were observed 
TABLE 2: Food intake, total energy intake, body weight, and liver, kidney, and perirenal fat tissue weight.

\begin{tabular}{lccc}
\hline Group & $\mathrm{CD}^{1}$ & $\mathrm{AD}^{2}$ & $\mathrm{LD}^{3}$ \\
\hline Food intake (g/day) & $17.2 \pm 0.66^{\mathrm{a}}$ & $10.9 \pm 0.95^{\mathrm{b}}$ & $11.0 \pm 0.91^{\mathrm{b}}$ \\
Total energy intake (Kcal) & $2040 \pm 780^{\mathrm{a}}$ & $1382 \pm 121^{\mathrm{b}}$ & $1400 \pm 116^{\mathrm{b}}$ \\
Total energy intake (Kcal/day) & $75.5 \pm 2.89^{\mathrm{a}}$ & $51.2 \pm 4.48^{\mathrm{b}}$ & $51.9 \pm 4.29^{\mathrm{b}}$ \\
Final body weight (g) & $40.2 \pm 1.39^{\mathrm{a}}$ & $29.8 \pm 2.73^{\mathrm{c}}$ & $34.5 \pm 3.41^{\mathrm{b}}$ \\
Liver weight (g/100 g BW) & $4.45 \pm 1.54$ & $4.85 \pm 1.01$ & $5.05 \pm 1.86$ \\
Kidney weight (g/100 g BW) & $0.59 \pm 0.08$ & $0.74 \pm 0.08$ & $0.68 \pm 0.22$ \\
Perirenal fat tissue weight (g/100 g BW) & $0.88 \pm 0.19^{\mathrm{a}}$ & $0.33 \pm 0.12^{\mathrm{b}}$ & $0.34 \pm 0.21^{\mathrm{b}}$ \\
\hline
\end{tabular}

${ }^{1} \mathrm{CD}$, control diet; ${ }^{2} \mathrm{AD}$, alcohol diet; ${ }^{3} \mathrm{LD}, L b$. paracasei-containing alcohol diet. Values represent mean $\pm \mathrm{SD}, n=8$. Values not sharing a common superscript letter are significantly different at $p<0.05$.

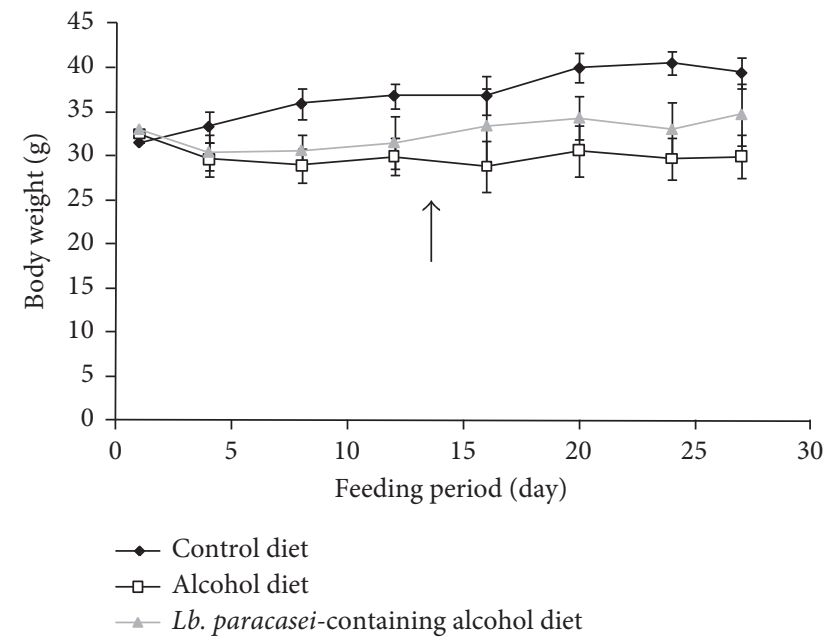

FIGURE 2: Body weight of mice during the experiment $(n=8)$. Arrow: start of restraint stress.

in fecal T-cho concentrations, but the fecal bile acids of the $\mathrm{AD}$ group were lower than those of the CD and LD groups $(p<0.05)$ (Table 4).

3.4. Kidney Histology. There were no differences in kidney tissue between the three groups in H\&E staining (data not shown). However, more fibrosis was observed in the glomerulus of the kidney in the $\mathrm{AD}$ group than in the other two groups in azan stain (Figures 4(a)-4(c)). Immunostaining results confirmed that the brown areas indicating the existence of mesangial cells were increased in the AD group but was almost nonexistent in the $\mathrm{CD}$ and $\mathrm{LD}$ groups (Figures 4(d)-4(f)). The average of the number of mesangial cells in the glomerulus of the $\mathrm{CD}, \mathrm{AD}$, and $\mathrm{LD}$ groups was $3.08 \pm 1.02,4.06 \pm 1.07$, and $3.39 \pm 0.90$, respectively. The number of mesangial cells in the AD group was significantly higher than those of the CD and LD groups $(p<0.001)$.

\section{Discussion}

We found that live $L b$. paracasei NFRI 7415 is beneficial for improving liver damage due to chronic alcohol intake [12]. In the current study, we investigated whether heat-killed $L b$. paracasei NFRI 7415 influenced kidney and bone in mice fed an ethanol-containing diet with stress. The perirenal fat tissue weights of the $\mathrm{AD}$ and $\mathrm{LD}$ groups were lower than that of the CD group $(p<0.05)$ (Table 2$)$. It is known that chronic alcohol intake and excessive stress accelerate energy metabolism in the body [21]. The final body weight of the AD group demonstrated frequently observed symptoms such as weight loss compared to be in the LD group. Intake of $L b$. paracasei NFRI 7415 may have prevented enhanced energy metabolism by alcohol intake and excessive stress.

Fermented dairy products such as yogurt utilizing LAB have been reported to lower serum cholesterol concentrations in animals [22]. We also reported that live $L b$. paracasei NFRI 7415 reduced the plasma T-cho and hepatic T-cho concentration in rats fed an ethanol-containing diet [12]. In this study, $\mathrm{LAB}$ were not found to lower plasma lipids. However, in terms of cholesterol-reducing activity, effects against liver lipids and the plasma GOT level were observed in the LD group receiving heat-killed $L b$. paracasei NFRI 7415. Plasma GOT and GPT are enzymes recognized as indicators of hepatitis, liver cirrhosis, and cardiac infarction [23]. Levels of these enzymes increase with liver cell damage, as in hepatitis. Thus, these results indicate that heat-killed $L b$. paracasei NFRI 7415 decreased the plasma GOT level and liver cholesterol concentration caused by chronic alcohol consumption.

As described in our previous paper, the live $L b$. paracase $i$ NFRI 7415 has the capacity to lower fecal T-cho excretion, and it effectively reduced plasma T-cho concentration [24]. Although no significant difference in fecal T-cho concentrations were observed here, the bile acid level of feces in the LD group increased (Table 4). This increase in the bile acid level appears to have been due to bile acid adsorption by LAB in the intestine $[25,26]$. Hence, it suggested that heat-killed Lb. paracasei NFRI 7415 had strong bile acid adsorption ability in feces.

Restraint stress load causes osteoporosis, due to an increase in the corticosteroid hormone secreted by the cortex of the adrenal gland, and increases bone resorption [27]. Heavy alcohol consumption has been associated with increased risk of bone fracture [3]. It is known that osteoporotic bones are more likely to fracture, and it is important to determine the bone content in mice fed alcoholcontaining diets with restraint stress.

In this experiment, the ash content in the bone of the $\mathrm{AD}$ group was lower than those of the other two groups $(p<0.05)$ (Table 4). Although there were no significant differences in right femur weight, or in calcium and phosphorus in bone, 
Table 3: Plasma lipids and liver lipids.

\begin{tabular}{lccc}
\hline Group & $\mathrm{CD}^{1}$ & $\mathrm{AD}^{2}$ & $\mathrm{LD}^{3}$ \\
\hline Plasma lipids & & & $141.0 \pm 42.0$ \\
Triacylglycerol (mg/dL) & $143.5 \pm 23.8$ & $126.2 \pm 14.8^{\mathrm{b}}$ & $176.3 \pm 91.6$ \\
Total cholesterol (mg/dL) & $167.4 \pm 33.8^{\mathrm{a}}$ & $90.9 \pm 12.9^{\mathrm{b}}$ & $179.2 \pm 25.5^{\mathrm{a}}$ \\
HDL-cholesterol (mg/dL) & $127.9 \pm 18.7^{\mathrm{a}}$ & & $120.8 \pm 23.8^{\mathrm{a}}$ \\
Liver lipids & & $76.9 \pm 25.3$ & $79.0 \pm 16.4$ \\
Total fat (mg/g) & $75.4 \pm 18.4$ & $28.6 \pm 12.6$ & $33.3 \pm 12.0$ \\
Triacylglycerol (mg/g) & $27.5 \pm 12.4$ & $11.1 \pm 3.60^{\mathrm{a}}$ & $6.37 \pm 1.80^{\mathrm{b}}$ \\
Total cholesterol $(\mathrm{mg} / \mathrm{g})$ & $8.69 \pm 3.46^{\mathrm{ab}}$ & \\
\hline
\end{tabular}

${ }^{1} \mathrm{CD}$, control diet; ${ }^{2} \mathrm{AD}$, alcohol diet; ${ }^{3} \mathrm{LD}, L b$. paracasei-containing alcohol diet. Values represent mean $\pm \mathrm{SD}, n=8$. Values not sharing a common superscript letter are significantly different at $p<0.05$.
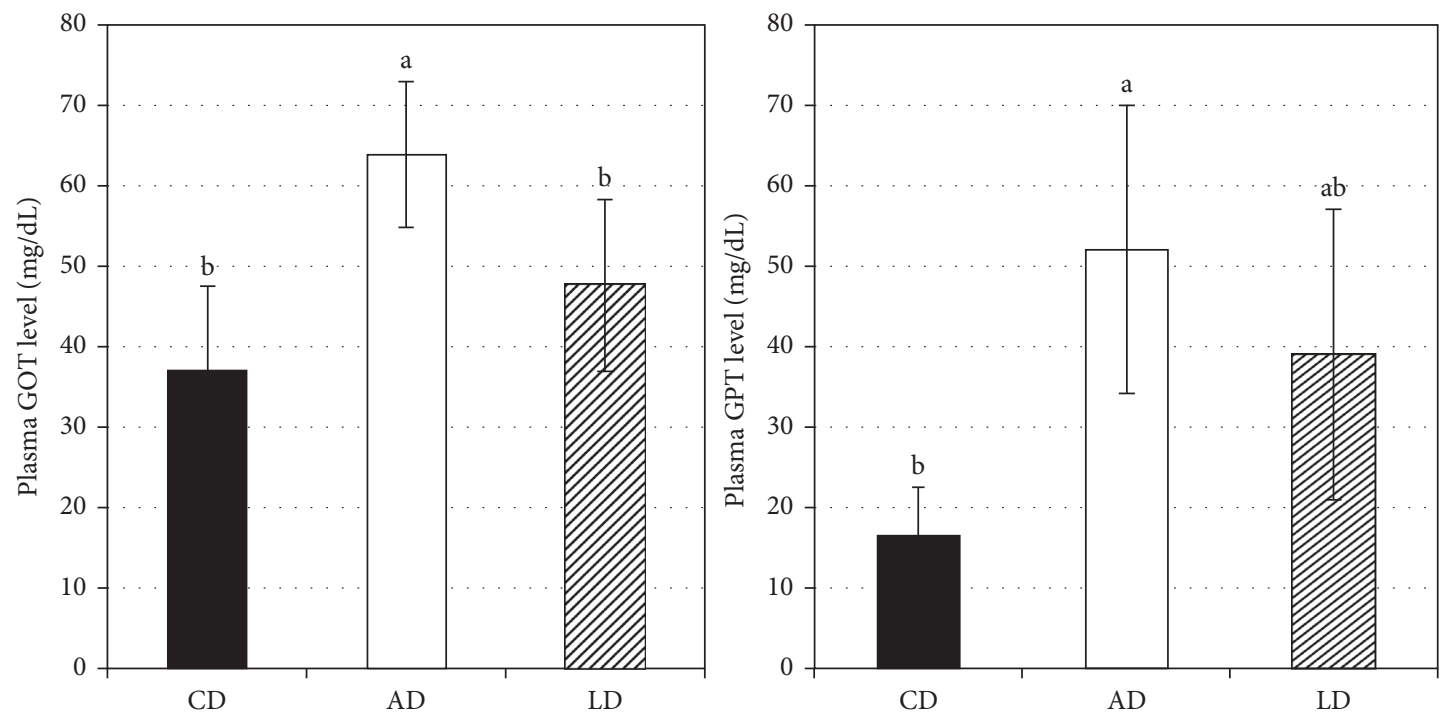

FIGURE 3: Plasma GOT level and plasma GPT level concentration of mice fed experimental diets. CD, control diet; $\mathrm{AD}$, alcohol diet; LD, $L b$. paracasei-containing alcohol diet. Values represent mean $\pm \mathrm{SD} ; n=8$. Values not sharing a common superscript letter are significantly different at $p<0.05$.

TABle 4: Bone content, plasma calcium, and fecal lipids.

\begin{tabular}{|c|c|c|c|}
\hline Group & $\mathrm{CD}^{1}$ & $\mathrm{AD}^{2}$ & $\mathrm{LD}^{3}$ \\
\hline \multicolumn{4}{|l|}{ Bone contents } \\
\hline Right femur weight (dry) (mg) & $57.4 \pm 6.23$ & $53.0 \pm 7.85$ & $56.1 \pm 5.56$ \\
\hline Right femur weight (defatted) (mg) & $53.6 \pm 6.0$ & $49.3 \pm 6.76$ & $52.3 \pm 5.30$ \\
\hline Ash (\%) & $53.0 \pm 1.44^{\mathrm{a}}$ & $50.9 \pm 2.13^{\mathrm{b}}$ & $54.0 \pm 2.67^{\mathrm{a}}$ \\
\hline Calcium (mg/g) & $13.3 \pm 0.85$ & $12.7 \pm 1.07$ & $13.0 \pm 0.77$ \\
\hline Phosphorus (mg/g) & $15.7 \pm 1.23$ & $14.6 \pm 1.34$ & $15.4 \pm 0.92$ \\
\hline Plasma calcium (mg/g) & $3.09 \pm 0.58$ & $4.06 \pm 0.62$ & $3.54 \pm 1.46$ \\
\hline \multicolumn{4}{|l|}{ Fecal lipids } \\
\hline Total fat (mg/g) & $48.2 \pm 9.30^{\mathrm{a}}$ & $29.8 \pm 10.9^{\mathrm{b}}$ & $39.9 \pm 9.77^{\mathrm{ab}}$ \\
\hline Bile acid $(\mu \mathrm{g} / \mathrm{g})$ & $3.54 \pm 0.99^{\mathrm{a}}$ & $2.38 \pm 0.56^{\mathrm{b}}$ & $3.91 \pm 0.74^{\mathrm{a}}$ \\
\hline Total cholesterol (mg/g) & $1.87 \pm 0.43$ & $1.89 \pm 0.56$ & $1.90 \pm 0.41$ \\
\hline
\end{tabular}

${ }^{1} \mathrm{CD}$, control diet; ${ }^{2} \mathrm{AD}$, alcohol diet; ${ }^{3} \mathrm{LD}, \mathrm{Lb}$. paracasei-containing alcohol diet. Values represent mean $\pm \mathrm{SD}, n=8$. Values not sharing a common superscript letter are significantly different at $p<0.05$. 


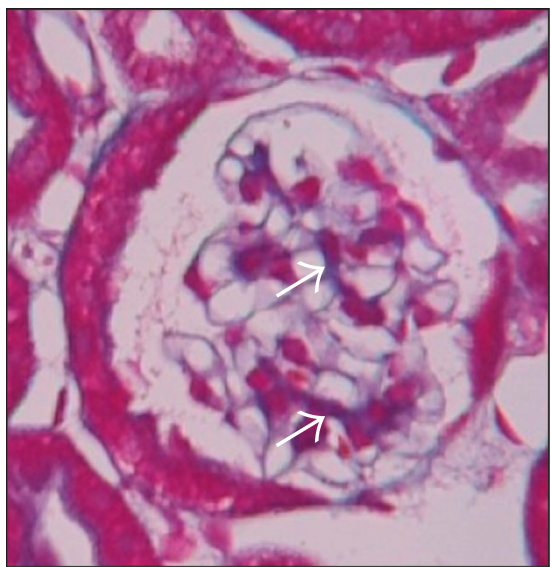

(a)

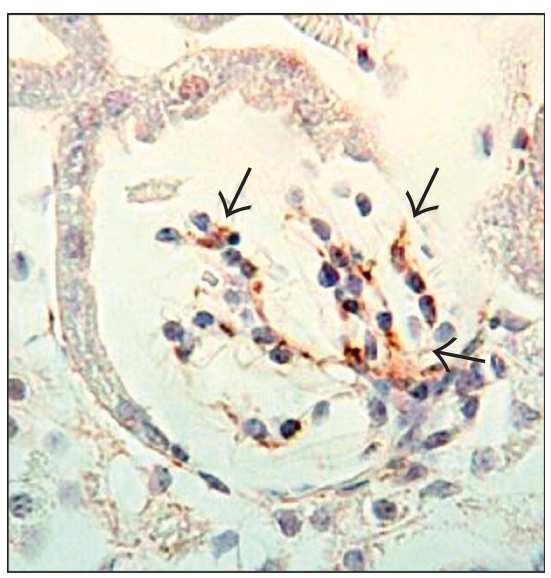

(d)

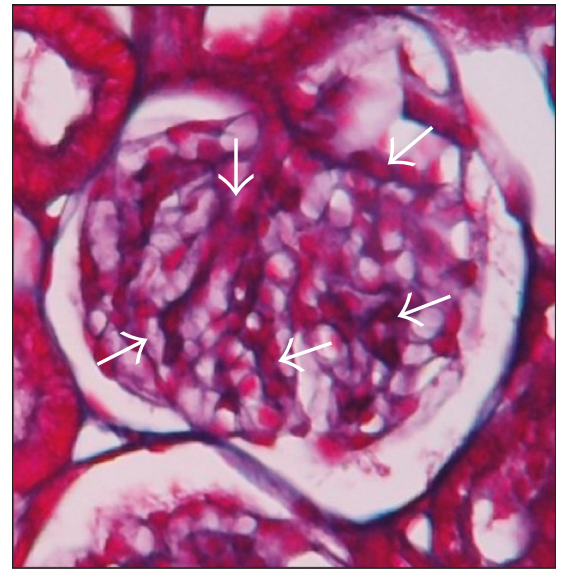

(b)

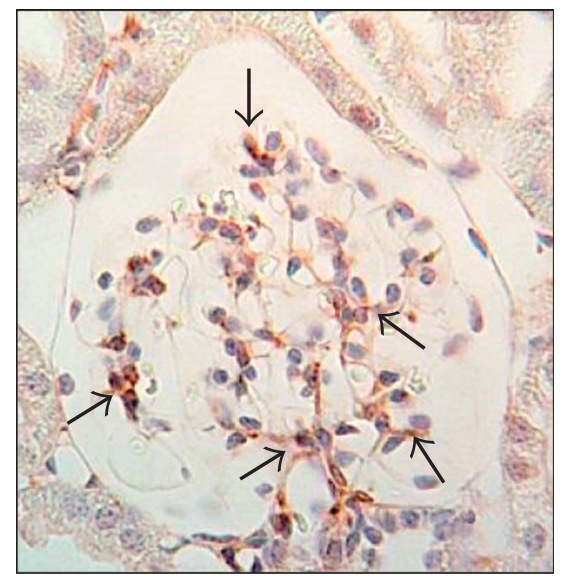

(e)

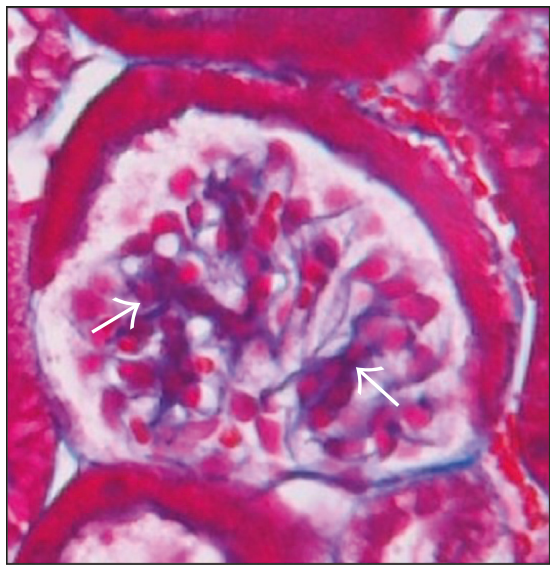

(c)

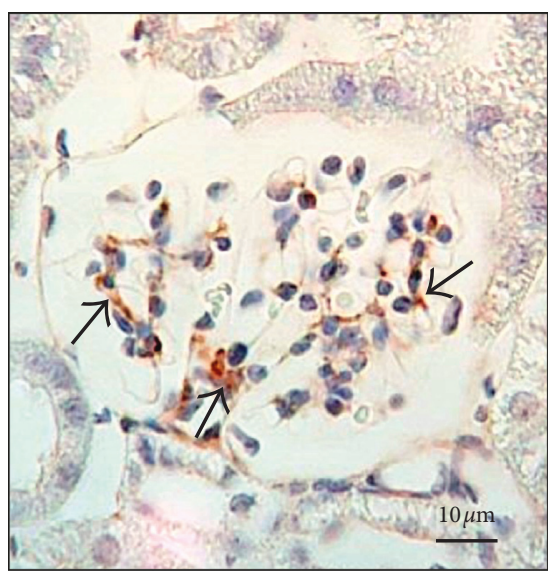

(f)

Figure 4: Mesangiolysis in mice. (a)-(c) Azan staining of the glomerulus in the kidney. (a) The glomerulus in the kidney from a normal mouse fed with control diet (CD). Blue regions (white arrows) show collagen fiber. (b) The glomerulus in the kidney from a mouse fed with alcohol diet (AD). Blue regions (white arrows) show collagen fiber, which are increased compared to (a). (c) The glomerulus in the kidney from a mouse fed with AD containing Lb. paracasei. Blue regions (white arrows) show collagen fiber, which are reduced compared to (b). (d)-(f) Immunostaining of the glomerulus in the kidney. (d) The glomerulus in the kidney from a normal mouse fed CD. A mesangial cell (black arrow) is stained by desmin. (e) The glomerulus in the kidney from a mouse fed with $\mathrm{AD}$. The number of mesangial cells (black arrows) is higher than in the normal kidney (d). (f) The glomerulus in the kidney from a mouse fed $\mathrm{AD}$ containing $\mathrm{Lb}$. paracasei. The number of mesangial cells (black arrow) is fewer than that of animals fed $\mathrm{AD}$ (e).

each average value of the $\mathrm{AD}$ group was lower than those of the $\mathrm{CD}$ and $\mathrm{LD}$ groups. For example, the right femur weight (dry) of the $\mathrm{CD}, \mathrm{AD}$, and $\mathrm{LD}$ groups was $57.4 \pm 6.23 \mathrm{mg}$, $53.0 \pm 7.85 \mathrm{mg}$, and $56.1 \pm 5.56 \mathrm{mg}$, respectively. Moreover, the plasma calcium of $\mathrm{CD}, \mathrm{AD}$, and $\mathrm{LD}$ groups were $3.09 \pm$ $0.58 \mathrm{mg}, 4.06 \pm 0.62 \mathrm{mg}$, and $3.54 \pm 1.46 \mathrm{mg}$, respectively. These results indicate that some minerals were eluted from the bone of $\mathrm{AD}$ group, promoting bone resorption. On the other hand, the plasma calcium of the LD group tended to be lower, suggesting that bone resorption was inhibited by LAB. It was reported that probiotic yogurt containing strains of Lactobacillus casei, Lactobacillus reuteri, and Lactobacillus gasseri increased apparent calcium absorption and bone mineral content in rats [28]. These LAB strains produce certain prebiotics such as oligosaccharides that help new bone tissue to grow. Further investigation of the effects of live $L b$. paracasei NFRI 7415 as probiotics is needed.
It was observed that the $\mathrm{AD}$ group had lower urine volume than the $\mathrm{CD}$ group during the experimental period. Kidney function weakness was therefore suspected in the $\mathrm{AD}$ group. Fibrosis of the organization occurs to the organ that the whole body is approximately important except the brain. The organ that caused the fibrosis will eventually malfunction. This means that renal function decreases as kidney fibrosis advances [29]. We therefore performed azan staining to observe fibrosis of the kidney. The mesangium domain in the glomerulus of the kidney consists of mesangium cells and mesangium substrates, including type IV collagen. Collagen fiber is stained blue by azan staining. An increase of the mesangium domain was confirmed, by the increase in blue in the glomerulus of the $\mathrm{AD}$ group. We then attempted immunostaining using the desmin antibody, which can specifically stain mesangial cells. Many more mesangium cells, colored brown by 
immunostaining, were observed in the AD group compared to the CD and LD groups.

There are always mesangial cells in the glomerulus of the kidney. They maintain capillary vessels of the glomerulus of the kidney and work to regulate its ability to filter the blood. Most chronic glomerulonephritis involves mesangial proliferative glomerulonephritis (MesPGN), for which the characteristic is an increase of mesangial cells [30]. The causes of MesPGN development remain to be elucidated. It is thought, however, that immunoreaction is the factor that causes this condition. Mesangium proliferative glomerulonephritis developed in the $\mathrm{AD}$ group by alcohol intake with stress.

In conclusion, the present investigation shows that heatkilled Lb. paracasei NFRI 7415 inhibits mesangial proliferative glomerulonephritis by alcohol intake with stress. Further studies are needed to investigate in more detail with five dietary treatment groups: a control diet (CD) group, an alcohol diet $(\mathrm{AD})$ group, the $\mathrm{CD}$ diet with restraint stress group, the $\mathrm{AD}$ with restraint stress group, and the $\mathrm{AD}$ with restraint stress containing LAB group. This is needed to clarify the relationship between restraint stress and risk of MesPGN.

\section{Conflicts of Interest}

The authors have no conflicts of interest to report.

\section{References}

[1] Ministry of Health, Labour and Welfare, Japan, The National Livelihood Survey in Japan 24-26, 2014, in Japanese.

[2] Ministry of Health, Labour and Welfare, Japan, The National Health and Nutrition Survey in Japan, Daiichi Press, Tokyo, Japan, 2014, in Japanese.

[3] E. G. Reimers, G. Q. Platt, E. R. Rodriguez, A. M. Riera, J. A. Negrin, and F. S. Fernandez, "Bone changes in alcoholic liver disease," World Journal of Hepatology, vol. 7, no. 9, pp. 1258-1264, 2015.

[4] K. Kaartinen, O. Niemela, J. Syrjanen et al., "IgA immune responses against acetaldehyde adducts and biomarkers of alcohol consumption in patients with IgA glomerulonephritis," Alcoholism: Clinical and Experimental Research, vol. 33, no. 7, pp. 1231-1237, 2009.

[5] H. Peters, S. Martini, R. Woydt et al., "Moderate alcohol intake has no impact on acute and chronic progressive antithy1 glomerulonephritis," American Journal of PhysiologyRenal Physiology, vol. 284, no. 5, pp. F1105-F1114, 2003.

[6] I. Elmadfa, P. Klein, and AL. Meyer, "Immune-stimulating effects of lactic acid bacteria in vivo and in vitro," Proceedings of the Nutrition Society, vol. 69, no. 3, pp. 416-420, 2010.

[7] X. Zhao, Y. Qian, H. Suo et al., "Preventive effect of Lactobacillus fermentum Zhao on activated carbon-induced constipation in mice," Journal of Nutritional Science and Vitaminology, vol. 61, no. 2, pp. 131-137, 2015.

[8] N. H. Kim, P. D. Moon, S. J. Kim et al., "Lipid profile lowering effect of Soypro ${ }^{\mathrm{TM}}$ fermented with lactic acid bacteria isolated from kimchi in high-fat diet-induced obese rats," BioFactors, vol. 33, no. 1, pp. 49-60, 2008.

[9] K. Parvaneh, M. Ebrahimi, M. R. Sabran et al., "Probiotics (Bifidobacterium longum) increase bone mass density and upregulate sparc and Bmp-2 genes in rats with bone loss resulting from ovariectomy," BioMed Research International, vol. 2015, Article ID 897639, 10 pages, 2015.

[10] R. Yacoub, D. Kaji, S. N. Patel et al., "Association between probiotic and yogurt consumption and kidney disease: insights from NHANES," Nutrition Journal, vol. 15, p. 10, 2016.

[11] N. Komatsuzaki, J. Shima, S. Kawamoto, H. Momose, and T. Kimura, "Production of $\gamma$-aminobutyric acid (GABA) by Lactobacillus paracasei isolated from traditional fermented foods," Food Microbiology, vol. 22, no. 6, pp. 497-504, 2005.

[12] N. Komatsuzaki and J. Shima, "Effects of live Lactobacillus paracasei on plasma lipid concentration in rats fed ethanolcontaining diet," Bioscience, Biotechnology, and Biochemistry, vol. 76, no. 2, pp. 232-237, 2012.

[13] N. Komatsuzaki, Y. Yamada, Y. Ueki, J. Shima, and S. Morikawa, "Lactobacillus paracasei NFRI 7415 reduces liver lipid contents in C57BL/6J mice fed a high-fat diet," International Journal of Clinical Nutrition and Dietetics, vol. 2, no. 1, p. 108, 2016.

[14] K. Yagasaki, "Nutritional and bromacological studies of food factors using in vitro and in vivo disease models," Journal of Japan Society of Nutrition and Food Sciences, vol. 62, no. 2, pp. 61-74, 2009.

[15] K. Fujisawa, K. Yagasaki, Y. Miura, and R. Funabiki, "Improvement of hyperlipidemia and proteinuria without noticeable growth retardation by feeding a methionine and threonine supplemented low-casein diet to nephritic rats," Bioscience, Biotechnology, and Biochemistry, vol. 59, no. 10, pp. 1896-1900, 1995.

[16] C. S. Lieber and L. M. DeCarli, "Liquid diet technique of ethanol administration," Alcohol and Alcoholism, vol. 24, no. 3, pp. 197-211, 1989.

[17] P. N. De Francesco, S. Valdivia, A. Cabral et al., "Neuroanatomical and functional characterization of CRF neurons of the amygdala using a novel transgenic mouse model," Neuroscience, vol. 289, pp. 153-165, 2015.

[18] J. Folch, M. Lees, and G. H. Sloane-Stanley, "A simple method for the isolation and purification of total lipids from animal tissues," Journal of Biological Chemistry, vol. 226, no. 1, pp. 497-509, 1957.

[19] H. Horikawa, T. Masumura, E. Watanabe, and T. Ishibashi, "Effects of dietary gizzerosine on contents of ash and calcium in the femur of young and ovariectomized mice," Journal of Animal Science and Technology, vol. 64, pp. 8-12, 1992.

[20] K. Iwami, N. Fujii, T. Suzuka, and R. Kanamoto, "Crucial role of soybean resistant protein in increased fecal steroid excretion and structural peculiarity of caught bile acids," Soy Protein Research, vol. 5, pp. 58-62, 2002, in Japanese.

[21] T. Sako, T. Sasaki, I. Hamaoka et al., "The effects of acute alcohol intake on energy metabolism in human skeletal muscle," Japan Women's University Journal, vol. 57, pp. 6772, 2010, in Japanese.

[22] A. S. Akalin, S. Gonc, and S. Duzel, "Influence of yogurt and acidophilus yogurt on serum cholesterol levels in mice," Journal of Dairy Science, vol. 80, no. 11, pp. 2721-2725, 1997.

[23] J. S. Byun and W. I. Jeong, "Involvement of hepatic innate immunity in alcoholic liver disease," Immune Network, vol. 10, no. 6, pp. 181-187, 2010.

[24] N. Komatsuzaki, K. Ebihara, M. Honda, Y. Ueki, and J. Shima, "Effects of lactic acid bacteria isolated from Japanese fermented fish (funa-sushi) on fecal cholesterol excretion of mice," Journal for the Integrated Study of Dietary Habits, vol. 25, no. 2, pp. 87-91, 2014, in Japanese.

[25] R. Kitawaki, Y. Nishimura, N. Takagi, M. Iwaki, K. Tsuzuki, and M. Fukuda, "Effects of Lactobacillus fermented soymilk 
and soy yogurt on hepatic lipid accumulation in rats fed a cholesterol-free diet," Bioscience, Biotechnology, and Biochemistry, vol. 73, no. 7, pp. 1484-1488, 2009.

[26] Y. H. Park, G. K. Jong, W. S. Young, H. K. Sae, and Y. W. Kwang, "Effect of dietary inclusion of Lactobacillus acidophilus ATCC 43121 on cholesterol metabolism in rats," Journal of Microbiology and Biotechnology, vol. 17, no. 4, pp. 655-662, 2007.

[27] F. Sakai, H. Suzuki, Y. Miyai, M. Yorita, M. Asano, and K. Takahashi, "Effects of restraint stress on ovalbumin-specific antibody titers and bone density in brown Norway rats," Journal of Japan Society of Nutrition and Food Sciences, vol. 67, pp. 87-94, 2014, in Japanese.

[28] K. E. Scholz-Ahrens, P. Ade, B. Marten et al., "Prebiotics, probiotics, and synbiotics affect mineral absorption, bone mineral content, and bone structure," Journal of Nutrition, vol. 137, no. 2, pp. 838S-846S, 2007.

[29] A. Kuma, M. Tamura, and Y. Otsuji, "Mechanism of and therapy for kidney fibrosis," Journal of UOEH, vol. 38, no. 1, pp. 25-34, 2016, in Japanese.

[30] T. Horino and Y. Terada, "Mesangial proliferative glomerulonephritis, endocapillary proliferative glomerulonephritis, crescentic glomerulonephritis," Journal of Japanese Society of Internal Medicine, vol. 98, pp. 1030-1041, 2012, in Japanese. 


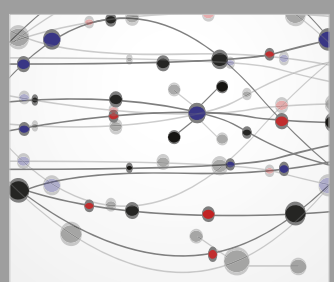

The Scientific World Journal
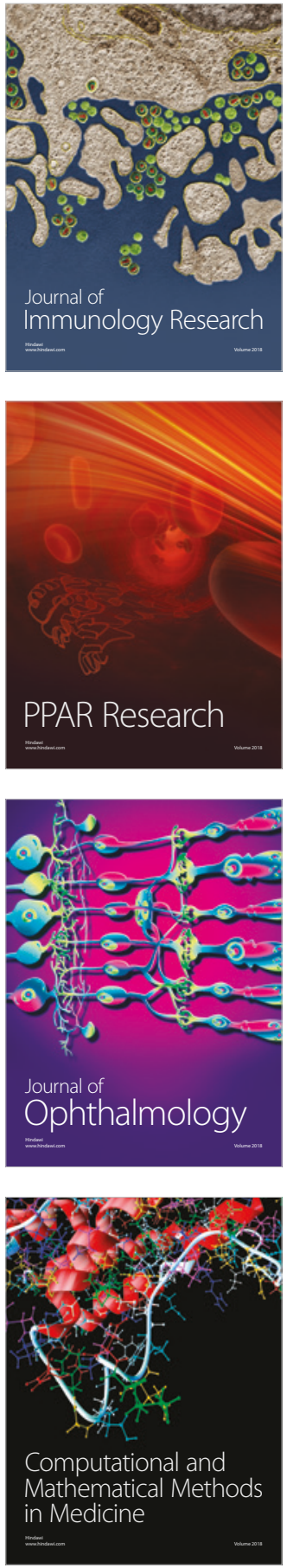

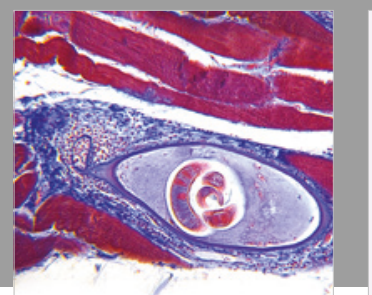

Gastroenterology Research and Practice

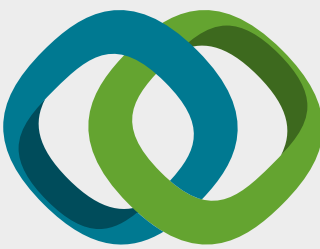

\section{Hindawi}

Submit your manuscripts at

www.hindawi.com
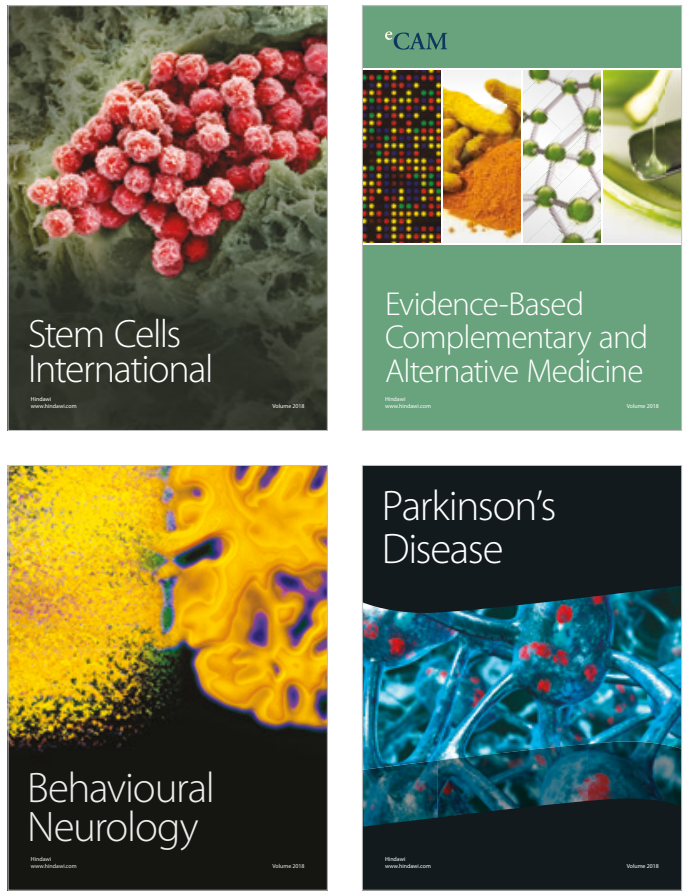

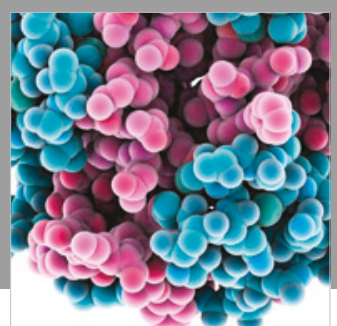

ournal of

Diabetes Research

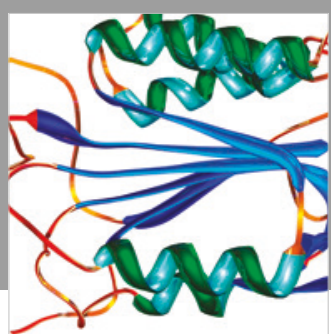

Disease Markers
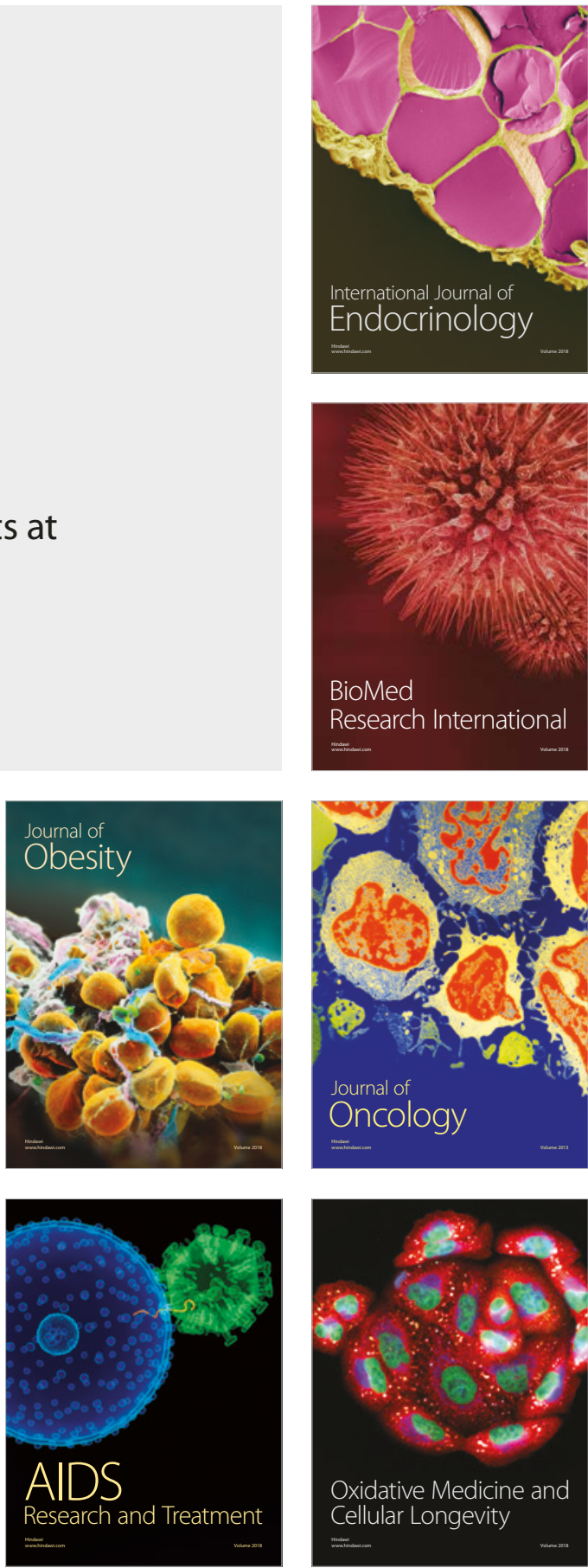